EGU21-2872, updated on 05 Apr 2021

https://doi.org/10.5194/egusphere-egu21-2872

EGU General Assembly 2021

(c) Author(s) 2021. This work is distributed under

the Creative Commons Attribution 4.0 License.

\title{
Evaluation of soil salinity and sodicity using electromagnetic conductivity imaging
}

Mohammad Farzamian ${ }^{1,2}$, Francisco José Martinez Moreno², Tiago B. Ramos ${ }^{3}$, Nadia Castanheira ${ }^{1}$, Ana Marta Paz ${ }^{1}$, Fernando A. Monteiro Santos ${ }^{2}$, Carlos A. Alexandre ${ }^{4}$, Maria Catarina $\mathrm{Paz}^{2,5}$, Mario Ramos Rodríguez ${ }^{6}, \mathrm{Karl}_{\text {Vanderlinden }}{ }^{6}$, and Maria C. Gonçalves ${ }^{1}$

${ }^{1}$ INIAV, Instituto Nacional de Investigação Agrária e Veterinária, Oeiras, Portugal, (mohammadfarzamian@gmail.com)

${ }^{2}$ Instituto Dom Luiz (IDL), Faculdade de Ciências, Universidade de Lisboa, Campo Grande, 1749-016, Lisboa, Portugal

${ }^{3}$ Universidade de Lisboa, Instituto Superior Técnico, Lisboa, Portugal

${ }^{4}$ Universidade de Évora, institute of Mediterranean Agricultural and Environmental Sciences, Évora, Portugal,

${ }^{5} \mathrm{ClQ}$ uiBio, Barreiro School of Technology, Polytechnic Institute of Setúbal, Rua Américo da Silva Marinho, 2839-001

Lavradio, Portugal

${ }^{6}$ IFAPA Centro Alameda del Obispo, Córdoba, Spain

In order to prevent further soil degradation, it is important to understand the processes controlling salinization. Salt related problems in soils can refer to an excess of soluble salts (saline soils), a dominance of exchangeable sodium in the soil exchange complex (sodic soils), or a mixture of both situations (saline-sodic soils). These categories are important because the impacts and management vary accordingly. Traditional soil sampling methods -which require boreholes for soil sampling and analysis- difficultly lead to a comprehensive answer to this problem. This is because they cover only small and localized sites and may not be representative of the soil properties at the management scales. Furthermore, they are highly time and work consuming, resulting in costly surveys. Geophysical techniques such as electromagnetic induction (EMI) provide enormous advantages compared to soil sampling because they allow for in-depth and noninvasive analysis, covering large areas in less time and at a lower cost.

EMI surveys were performed in several regions in Portugal with historic soil salinity and sodicity problems to evaluate the salinization risk. We inverted field apparent conductivity data $\left(\sigma_{a}\right)$ in order to obtain electromagnetic conductivity images $(\mathrm{EMCl})$ of the real soil electrical conductivity $(\sigma)$ in depth. We evaluated the potential of $\mathrm{EMCl}$ in the estimation of soil salinity, sodicity, and other soil properties over large areas across regions with a very different range of salinity and sodicity.

\section{Acknowledgments}

This work was developed in the scope of SOIL4EVER "Sustainable use of soil and water for improving crops productivity in irrigated areas" project supported by FCT, grant no. PTDC/ASP- 
SOL/28796/2017. 